\title{
Do yoga para a atenção psicossocial na Atenção Primária à Saúde: um estudo hermenêutico sobre valores e princípios éticos do Yoga Sutra de Patañjali
}

\author{
From yoga to psychosocial care in Primary Health Care: \\ a hermeneutic study on the ethical values and principles \\ of the Yoga Sutras of Patañjali
}

Léo Fernandes Pereira (https://orcid.org/0000-0003-0441-9119) ${ }^{1}$

Charles Dalcanale Tesser (https://orcid.org/0000-0003-0650-8289) ${ }^{1}$

${ }^{1}$ Universidade Federal de Santa Catarina. R. Eng. Agronômico Andrei Cristian Ferreira s/n, Trindade. 88040-900 Florianópolis SC Brasil. leo.fernandes. pereira@gmail.com

\begin{abstract}
The scope of this article is to interpret ethical values and principles of the yoga tradition and discuss them with a view to possible contributions to psychosocial care in Primary Health Care (PHC). A theoretical-hermeneutic study was conducted, in which concepts contained in the Yoga Sutras of Patañjali were interpreted from the standpoint of mental health. It was revealed that the values found in the texts can enrich the existing practices of yoga for PHC users (who suffer from afflictions inherent to life) by providing ideas and guidelines that promote a sense of liberation from suffering. Such values and ethical principles can be incorporated into the discussions in PHC and psychosocial care, such as the reduction of iatrogenic disorders and unnecessary medication (quaternary prevention). It can also contribute to the relativization of biomedical power, stimulation of empathy and participation of users in care, with their subjective repositioning, multiplying autonomous ways of managing suffering and building networks of psychosocial support. The conclusion drawn was that the values of the Yoga Sutras may be present in various domains of PHC, which might provide a broader understanding of what 'the practice of yoga' means.

Key words Yoga, Primary Health Care, Complementary Therapies, Mental health
\end{abstract}

Resumo O presente artigo tem como objetivo interpretar valores e princípios éticos da tradição do yoga e discuti-los visando possíveis contribuições para a atenção psicossocial na Atenção Primária à Saúde (APS). Foi realizado um estudo teórico-hermenêutico, em que conceitos presentes na escritura Yoga Sutra de Patañjali foram interpretados sob o enquadramento da saúde mental. Constatou-se que os valores encontrados na escritura podem enriquecer as práticas de yoga atualmente existentes voltadas para os usuários da APS (que sofrem com aflições inerentes à vida) ao fornecerem ideias e diretrizes que favorecem um sentido de libertação do sofrimento. Tais valores e princípios éticos podem ser incorporados às discussões presentes na APS e na atenção psicossocial, como redução da iatrogenia e da medicalização desnecessária (prevenção quaternária), relativização do poder biomédico, estímulo ao exercício da empatia e da participação dos usuários nos cuidados, com seu reposicionamento subjetivo, pluralizando formas autônomas de manejo do sofrimento e construindo redes de apoio psicossocial. Concluiu-se que os valores do Yoga Sutra podem estar presentes em diversos âmbitos da APS, o que daria um entendimento expandido sobre o que significa uma "prática de yoga".

Palavras-chave Ioga, Atenção Primária à Saúde, Terapias Complementares, Saúde mental 


\section{Introdução}

Conhecido na Índia como uma filosofia prática de abordagem holística, o yoga vem se expandindo no campo da Atenção Primária a Saúde (APS), à medida em que seus efeitos benéficos para a saúde física e mental são divulgados pelos seus usuários e pela comunidade científica. Em 2017, em conjunto com outras práticas correlatas, como meditação e o sistema médico indiano Ayurveda, o yoga ingressou oficialmente, através da portaria no 849/MS, no rol das Práticas Integrativas e Complementares (PIC) a serem ofertadas nos serviços do SUS, sobretudo na APS $^{1,2}$. Embora as ações da APS não se limitem a um espaço físico específico, no Brasil este nível de atenção está muito associado aos Centros de Saúde, que são locais onde ocorrem diversas ações de proteção da saúde, prevenção de agravos, diagnóstico e tratamento, além de ações de promoção da saúde, como possíveis grupos de yoga, geralmente conduzidos por um profissional de saúde interessado na prática.

Nos Centros de Saúde também são realizadas atividades voltadas à saúde mental, que, de acordo com a perspectiva psicossocial, devem valorizar "ações que têm como eixos centrais o fortalecimento da autonomia e o enfoque na subjetividade, o incentivo à participação em atividades comunitárias, as PIC e os grupos de apoio"3. Nesse sentido, é constatada uma convergência, ou 'afinidade eletiva' no sentido weberiano do termo, entre a proposta das PIC, dentre as quais o yoga se situa, o projeto político-institucional da APS e o modelo psicossocial de cuidado à saúde mental, já que essas três vertentes têm como pressuposto o protagonismo e responsabilidade da pessoa frente às suas condutas de cuidado, prevenção e promoção da saúde. Esses pressupostos produzem encontros mais dialógicos e participativos entre profissional e usuário, além de serem permissivos às diferentes abordagens em saúde ${ }^{4}$.

A valorização da dimensão experiencial e psicossocial do sujeito faz parte do que Caprara ${ }^{5}$ entende por perspectiva hermenêutica do modelo saúde-doença. Tal perspectiva concebe a ansiedade, queixa encontrada frequentemente na APS, não como um sintoma patológico, um problema apenas de ordem biológica ou comportamental, mas também como algo que reflete a procura pelo autoconhecimento e por um novo significado de vida ${ }^{5}$.

Na filosofia do yoga, a ansiedade e outras aflições humanas são, em grande parte, consideradas expressões de uma ignorância fundamental (avi- $d y a)$, que diz respeito ao desconhecimento do sujeito em relação a sua natureza de plenitude. Essa ignorância gera uma cisão entre o 'individuo' e o 'mundo', dotando o sujeito de identificações com sua perspectiva em relação ao mundo e com as condições físicas e mentais que são experienciados por ele. A filosofia do yoga afirma que, por serem efêmeras e limitadas, tais condições e experiências não são constituintes essenciais do sujeito. Tradicionalmente, o yoga é considerado uma ferramenta de apoio para o que seria uma solução definitiva, que consiste na erradicação dessa ignorância fundamental, também chamada de "libertação" (moksha). Como desdobramento secundário dessa libertação, emergiria uma sabedoria e uma tranquilidade em relação aos desfechos e dramas da vida ${ }^{6}$.

Na escritura Yoga Sutra de Patañjali, considerada um dos cânones do yoga, constam diretrizes e princípios éticos que servem para que a pessoa desenvolva uma relativa tranquilidade mental necessária para a libertação do sofrimento. Considerando o momento atual de globalização do yoga, em que seus exercícios físicos são destacados como promotores de saúde física e mental, existe, por parte de estudiosos contemporâneos, uma preocupação em preservar os seus aspectos filosóficos e espirituais, como forma de manter em vista o seu objetivo primário ${ }^{7,8}$. Por outro lado, no contexto da APS, constata-se a necessidade de inserir práticas não-médicas que, assim como na filosofia do yoga, tenham o potencial para re-humanizar o sofrimento, concebendo-o também como um constituinte gnosiológico do processo de saúde e doença ${ }^{9}$.

Neste artigo pretende-se explorar os primeiros dois componentes do sistema de yoga proposto por Patañjali, chamados na língua sânscrita de yamas e niyamas. Estes componentes tratam dos valores e princípios éticos que a pessoa deve estabelecer consigo e com o meio social para o desenvolvimento de uma maior tranquilidade mental. Partimos da hipótese que o resgate dos conceitos presentes nesses componentes pode fornecer subsídios para o aprimoramento da produção de cuidado em saúde mental na APS.

\section{Metodologia}

Foi realizado um estudo teórico-hermenêutico utilizando o método textual literário. Este método está voltado para a interpretação de um texto específico ou grupo de textos, fazendo uso de um quadro interpretativo particular ${ }^{10}$. No caso 
da pesquisa, o corpus escolhido foi a escritura Yoga Sutra, especificamente os versos 2.30 e 2.31, que foram interpretados sob o enquadramento da saúde mental, com vistas a sua aplicação na atenção psicossocial no contexto da APS. O Yoga Sutra é um texto presente na tradição indiana, escrito na língua sânscrita e de autoria atribuída ao sábio Patañjali, personagem do qual pouco se pode afirmar quanto à sua biografia, mas se pode supor que se tratava de uma grande autoridade em yoga e estudioso das escrituras antigas. O Yoga Sutra, escrito provavelmente no século II d.C, está composto na forma versos curtos, agrupados em quatro capítulos, que abordam a teoria e prática do yoga em uma linguagem metódica e objetiva $^{11}$.

Seguindo o método hermenêutico, foram utilizados dois processos necessários à interpretação dos conteúdos do Yoga Sutra, que compõem o chamado "círculo hermenêutico". O primeiro diz respeito ao processo dialético e circular que ocorre entre o pesquisador e o tópico da pesquisa. O círculo hermenêutico é produzido através de uma criação conjunta entre o pesquisador e o objeto de estudo. O segundo processo relacionado ao círculo hermenêutico diz respeito à operação referencial, ou seja, a compreensão de que um conceito presente em um texto retira o seu significado de um contexto ou de um horizonte de sentidos no qual se situa. Um texto só pode ser interpretado através de suas partes, e suas partes não podem ser entendidas separadas do todo. Portanto, esses processos contínuos, entre as partes do texto, seu todo e o contexto, e entre texto e pesquisador, são conhecidos, no seu conjunto, por círculo hermenêutico ${ }^{8,12,13}$. Para este estudo, foram utilizados comentários clássicos e contemporâneos sobre a escritura, assim como outras referências que, juntamente com o Yoga Sutra, fazem parte da tradição do yoga. Foram utilizados autores da saúde coletiva que permitiram traçar um diálogo entre os valores presentes na escritura e o contexto da atenção psicossocial na APS.

\section{Resultados e discussão}

Os valores e princípios éticos fazem parte dos oito componentes do sistema de Patañjali que são apresentados no verso 2.29 de seu Yoga Sutra. De acordo com a tradução de Gulmini ${ }^{14}$ os componentes são: refreamentos (yama), observâncias (niyama), postura (asana), controle do alento (pranayama), retraimento dos sentidos (pratyahara), concentração (dharana), medita- ção (dhyana) e integração (samadhi). Em verso anterior, Patañjali esclarece que estes componentes serviriam para remover "impurezas" que impedem a emergência do conhecimento discriminativo em relação a natureza do $\operatorname{ser}^{15}$. Já que a tradução dos dois primeiros componentes dada por Gulmini ${ }^{14}$ por refreamentos e observâncias, pode, em decorrência da nossa cultura cristã, carregar uma conotação de autopunição, de algo que vise uma "expiação de pecados", preferimos considerar os yamas e niyamas, de forma conjunta, como valores, no entendimento que tais disciplinas, no contexto do yoga, servem para desenvolver uma estrutura de valores na pessoa, fazendo com que ela possua uma tranquilidade mental necessária para o autoconhecimento. A diferença entre os dois componentes está no fato de que os niyamas são mais centrados em mudanças de conduta individuais e são disciplinas, ou valores, específicos do yoga, enquanto que a maioria dos yamas, além de se diferenciarem daqueles por utilizarem uma linguagem mais na negativa (comportamentos e atitudes que devem ser refreados), são compreendidos também como princípios éticos universais, pois geram transformações não somente no indivíduo, mas também ao nível do social. No verso 2.30 da escritura são listados os yamas (princípios éticos), que são: não-violência, veracidade, não-possessividade, continência e não-consumismo. Já os niyamas (valores yóguicos), citados no verso 2.32, são: pureza, contentamento, ascese, auto-estudo e contemplação à ishvara. Apresentamos a seguir a interpretação desses valores juntamente com uma discussão relacionando os mesmos com a atenção psicossocial e o cuidado na APS.

\section{Princípios éticos: yamas}

Conforme Vyasa, que é considerado o primeiro comentarista clássico do Yoga Sutra, todos os valores listados por Patañjali têm origem e servem para alcançar o princípio da não-violência, definido como o comprometimento de se evitar cometer agressões de ordem física, verbal ou mental ${ }^{15,16}$. Por possuir uma psicologia centrada na pessoa $^{17}$, o enfoque do yoga normalmente se restringe ao plano individual da violência, prezando por mudanças comportamentais como a adoção de uma postura pacífica, deixando a desejar discussões mais aprofundadas sobre a violência estrutural; aquilo que é definido como sendo os arranjos sociais que, arraigados na cultura, oprimem indivíduos ou grupos específicos, impedindo-os de alcançarem o seu potencial pleno ${ }^{18}$. 
No âmbito da atenção psicossocial, essa diretriz yóguica poderia servir para questionar a cultura da supermedicalização da saúde mental, em que os sofrimentos e sintomas psíquicos são comumente reduzidos a componentes constituintes de "transtornos", os quais são merecedores de pura supressão, contenção ou controle via psicofármacos, na suposição de que sua eliminação ou redução e controle significa automaticamente sucesso terapêutico.

Como regra geral, as formas de tratamento de transtornos ou sintomas mentais via psicofármacos podem ser consideradas em certa medida violentas, uma vez que produzem, ao menos em parte, uma simples eliminação da percepção do(s) sintoma(s), com alguma desconexão do sujeito de sua própria experiência e subjetividade (supressão do contato com suas aflições), transferindo a potência terapêutica para o manejo profissional heterônomo medicamentoso, o que a princípio é indesejável. Assim, os psicotrópicos, nessa linha da não-violência, seriam preliminarmente afastados como sintomáticos perigosos de efeitos adversos, só justificáveis em situações extremas e pelo mínimo tempo possível, em que se considere que o benefício esperado supere os prejuízos e efeitos adversos. Isso não proíbe o seu uso, mas cria uma visão alternativa típica da atenção psicossocial que inverte a hierarquia de preferências, altera os significados atribuídos ao seu uso e função e sua potência, e constrói um conjunto de valores éticos que mudam drasticamente sua desejabilidade; de opções preferenciais facilmente acionáveis para recursos indesejáveis e relativamente violentos, considerando-se o seu pouco fomento à ressignificação, maior autonomia e reelaboração das experiências, sensações, subjetividades e sofrimentos, movimentos estes que, de acordo com a perspectiva psicossocial, são desejáveis no cuidado na APS. Assim, o princípio da não-violência conflui para a construção de uma relação empática entre profissional e usuário, característica sabidamente e unanimemente desejável em alto grau nas interações terapêuticas, indo na direção da otimização e exploração do vínculo e das formas suaves e compartilhadas de cuidado, tratamento e ressignificação dos sentimentos, experiências e sofrimentos fomentadores do crescimento, amadurecimento e autonomia dos usuários.

O segundo princípio ético, traduzido por "veracidade", significa o compromisso que se deve ter em transmitir informações, perspectivas e sentimentos da maneira mais clara e fidedigna possível, fazendo uso de uma linguagem que seja não-violenta, agradável e benéfica ao ouvinte ${ }^{19}$. Quando presente nas relações humanas, a veracidade (ou sinceridade) permite o desenvolvimento da confiança mútua e da cumplicidade entre as partes, permitindo que se desenvolvam 'redes sociais de apoio', estruturas que por si só são consideradas terapêuticas, especialmente para a saúde mental. O conceito de rede social de apoio vem adquirindo proeminência junto com o discurso da reforma psiquiátrica, em que a lógica hospitalocêntrica e excludente utilizada para o tratamento de portadores de transtornos mentais vem sendo progressivamente substituída por uma assistência que preza pela integração social e familiar. De fato, toda pessoa (salvo, talvez, raras exceções) precisa de algum tipo de rede social de apoio. A existência de suportes sociais ativos e confiáveis parece ser uma prerrogativa para a saúde mental, uma vez que fornece ao indivíduo recursos para o enfrentamento de situações estressantes $^{20}$. Embora a veracidade, no contexto do yoga, esteja voltada mais para a capacidade de estabelecer relações honestas com o mundo, do que necessariamente para a criação de maiores redes de apoio, acredita-se que a criação de vínculos, balizados por esse princípio ético, facilita tal criação.

De maneira geral, salvo exceções importantes em relação a assuntos sensíveis, esse princípio ético aplicado no âmbito da atenção psicossocial se expressa através do uso de uma comunicação honesta, agradável e terapêutica, oportunizando, dessa maneira, a criação do vínculo entre profissional e usuário. Levantamos, aqui, uma cautela afinada com a disciplina do yoga, que preza pelo desenvolvimento da sensibilidade: diz respeito às diversas formas de comunicação não-verbal que o profissional transmite durante um atendimento, tais como postura corporal, tom de voz, distância pessoal, olhar e expressão facial que, ainda que muitas vezes inconscientes, podem ter um fator iatrogênico, minando a confiança mútua entre usuário e profissional se não forem bem lapidadas $^{21}$. Desse modo, a aplicação do princípio yóguico da veracidade também envolve uma tomada de consciência do profissional por parte dessas vias comunicativas e um empenho em alinhar pensamento, fala e ação, de forma que não existam ambiguidades no processo terapêutico. Outras observações relacionadas ao princípio da veracidade nessa situação seriam: evitar o emprego de palavras estrangeiras, incompreensivas ou mesmo incomuns ao ouvinte; e evitar um discurso com significado vago ou que confunda o ouvinte ${ }^{16}$. 
Além disso, sempre que pertinente, o profissional afinado com o modo psicossocial de cuidado em saúde mental deve buscar nutrir no usuário a criação de vínculo deste com sua família, no entendimento que é na família “(...) que as relações mais verdadeiras são estabelecidas e as soluções para os problemas podem ser elaboradas" ${ }^{20}$. No entanto (e talvez justamente por esse estabelecimento de relações mais verdadeiras), muitas das demandas de saúde mental encontradas na APS têm origem em desentendimentos familiares. Nesse caso, sabe-se que a atenção psicossocial deve manter como foco de cuidado a família e não somente o indivíduo aflito, sendo que a solução amiúde envolve o desenvolvimento da comunicação sincera e não violenta entre as partes envolvidas.

O terceiro princípio ético, asteya, significa 'não-roubar', mas, optamos por traduzi-lo por "não-possessividade", considerando que este princípio abrange qualquer forma de oportunismo, tais como considerar a posse de outra pessoa como sendo 'minha' para o aproveitamento da situação ${ }^{16}$, cortar a fila no trânsito, estacionar em vaga de deficiente e outras 'corruptelas' do cotidiano. Em um olhar ampliado, o princípio da não-possessividade poderia, inclusive, servir de crítica aos roubos/rombos e à falta de economia nos recursos naturais decorrentes do nosso estilo de vida baseado no consumo, depleções estas que frequentemente passam desapercebidas, mas que, de algum modo, afetam a nossa paz mental, produzindo uma gradual sensação de auto sufocamento junto com a ideia de que, como projeto de sociedade, "não estamos indo na direção apropriada”.

A não-possessividade tem relação próxima com o último princípio ético, traduzido (de maneira distinta) por nós como não-consumismo, pois em ambos os princípios existe uma crítica implícita, sutil e profunda sobre o estilo de vida voltado para a aquisição de bens (materiais e imateriais) e para a realização constante de desejos. Embora os processos sociais envolvidos na causa do desejo não sejam tema de discussão do Yoga Sutra e nem do yoga de forma geral, pensamos que é necessário considerá-los, se quisermos adotar uma perspectiva psicossocial sobre os valores do yoga. Por exemplo, tem sido reconhecida a função dos meios de comunicação de massa na produção de "falsas necessidades" e consequente geração de ansiedades através primeiro da medicalização de aspectos naturais da existência humana (fisiológicos e psicológicos, como a tristeza e a solidão), e depois da oferta de suas "soluções" para os problemas inventados ${ }^{22}$. Vários valores sociais disseminados pelos meios de comunicação de massa e pela estrutura social podem ser considerados relativamente pouco saudáveis, em que o estar acima dos demais, a crença na busca pelo sucesso social visto como acúmulo de poder e riqueza, a ambição e a ostentação, são constantemente difundidas. $\mathrm{O}$ poder de consumo e o empreendedorismo a todo custo se estendem à área da saúde, dificultando inclusive um mínimo de senso de limite para com o que é sustentável e necessário em termos de modo e ritmo de vida. Isso gera uma relação com a saúde e com os profissionais, técnicas e tecnologias de tratamento similar a relação para com o conjunto dos bens de consumo, vistos apenas como objetos a serem consumidos e meios para obtenção de fins prédeterminados que não remetem o sujeito a um contato consigo mesmo e seus valores e objetivos de vida.

Constata-se uma crescente dependência da população de serviços e produtos farmacêuticos, conforme se difunde a medicalização excessiva de experiências da vida e é expandido o mercado respaldado pelo complexo médico-industrial. $\mathrm{O}$ consumo de medicamentos psicotrópicos carrega o potencial de gerar alto grau de apego dos indivíduos aos serviços de saúde, processo que Illi$\mathrm{ch}^{23}$ denominou de iatrogenia cultural. Portanto, no contexto da saúde mental da APS, o desapego yóguico perpassaria por discussões críticas sobre o consumo de psicofármacos, como ansiolíticos, antidepressivos, do álcool e de outras drogas de adição, bem como sobre as "falsas necessidades" induzidas pelo mercado de consumo, que produzem, de maneira indireta, sentimento de vazio ou de ansiedade.

O último dos yamas é frequentemente traduzido por "continência” (brahmacharya). Vyasa define este valor como sendo "o controle sobre o órgão progenitor secreto" ${ }^{15}$. Embora comentaristas tradicionais do Yoga Sutra se refiram à prática da castidade ${ }^{16}$, é comum encontrarmos professores contemporâneos, como Arieira ${ }^{6}$, que optam por interpretar o termo brahmacarya ao pé da letra, que significaria algo como uma "conduta que leva ao Absoluto”. Já Iyengar ${ }^{24}$ define o termo como sendo o gerenciamento sobre a energia sexual, na compreensão que, historicamente, sempre houve yogues chefes de família. De qualquer forma, consideramos problemático discutir um tipo de regime que pode facilmente tomar contornos de bio-moralidade ${ }^{25}$ o que faz com que a nosso ver esse conceito tenha pouco cabimento no âmbito da atenção psicossocial na APS. Esse 
refreamento poderia servir, talvez, como um contraponto à ideologia de supevarlorização e superestimulação da sexualidade, características não raras em uma sociedade em que o sucesso a todo custo e a performance empreendedora parecem ser imperativos quase absolutos, o que pode gerar e também vem gerando aflições.

\section{Valores yóguicos: niyamas}

Tendo apresentado os yamas, Patañjali introduz cinco disciplinas específicas do yoga (nyamas), a começar pela "pureza" (sauca), entendida por Vyasa como sendo tanto ações de "purificação interna", que consiste no gerenciamento de emoções e sentimentos como orgulho, intolerância, apego e inimizade, através do cultivo de sentimentos opostos a estes, quanto de "purificação externa", tais como exercícios respiratórios, higienização corporal, jejuns e alimentação apropriada, sendo que ambos os tipos de purificação tem como propósito principal uma maior tranquilidade da mente ${ }^{16}$. A alimentação, por exemplo, é considerada no yoga uma ação purificadora, dependendo da atitude da pessoa e as características do alimento ingerido. Consta na Bhagavad Gita, livro considerado um dos cânones do yoga, que existem alimentos que causam agitação e inercia mental, e outros, considerados mais puros, que geram maior clareza e reflexividade $^{19}$.

A ideia trazida pelas escrituras de yoga de uma purificação mental através da alimentação poderia suscitar, no âmbito da atenção psicossocial, discussões sobre o uso de fitoterápicos e de uma alimentação saudável e orgânica. A fitoterapia ou o uso de plantas medicinais é um tipo de PIC que pode oferecer diversos recursos aos sujeitos que buscam os serviços de saúde para obterem alívio de seu sofrimento mental, sendo que alguns fitoterápicos aprovados pela Agência Nacional de Vigilância Sanitária (ANVISA) para uso no SUS são indicados para o tratamento de estados depressivos e de ansiedade leves, distúrbios do sono associados à ansiedade e casos de astenia em geral ${ }^{26}$. Para além disso, hortas comunitárias, contendo plantas medicinais, hortaliças e árvores frutíferas, configuram-se como espaços terapêuticos, de promoção da saúde mental e de educação em saúde da comunidade, além de servirem como fontes de matéria-prima ${ }^{27}$. Mais que possuírem um efeito terapêutico no próprio ato, pensamos que a ação de mexer na terra, plantar e comer alimentos colhidos diretamente dela, pode ter impactos positivos na saúde mental devido à ingestão de microrganismos que favorecem a microbiota intestinal, sendo que alguns deles, chamados de psicobióticos por estudos atuais, possuem efeitos ansiolíticos e antidepressivos ${ }^{28}$.

Existem diversas outras práticas de purificaçoes, oriundas principalmente do hatha yoga (vertente que se especializou em saberes psicofísicos) que podem ser utilizadas no contexto da atenção psicossocial, servindo como recursos na prevenção e tratamento de aflições consideradas leves e moderadas. Exercícios de respiração, como a simples observação do ato, servem para trazer a pessoa para o presente, possibilitando que ela se distancie de projeções negativas e temores que possam estar gerando as aflições. Uma prática presente no Yoga Sutra, de purificação interna, consiste no método de 'trazer uma atitude contrária', que significa a reconsideração deliberada de ideias acabadas que o sujeito tem sobre temas específicos, situações e pessoas ou de quaisquer pensamentos negativos, permitindo que se dissolvam emoções dolorosas e destrutivas que possam estar no cerne de suas queixas.

$\mathrm{O}$ segundo niyama, traduzido por contentamento (santosha), é definido por Vyasa como sendo a "ausência do desejo de garantir mais do que as necessidades de vida que alguém já possui” ${ }^{15}$. Aqui, uma questão emerge: Caso alguém não possua recursos mínimos para uma vida digna, seria possível o contentamento? Também, a definição dada sobre o contentamento não prevê a busca por melhorias nas condições de vida, tão precárias para boa parte da população brasileira. Se pensarmos que o acesso aos bens e serviços relacionados à saúde podem ser considerados, no seu conjunto, uma necessidade básica de vida que ainda está em construção no Brasil, precisamos, portanto, colocar a ideia de contentamento em perspectiva. Diríamos, inclusive, que é movido por um descontentamento pelas condições atuais dos serviços de saúde que movimentos sociais batalham por uma melhor distribuição da grande riqueza do país e pela garantia de um SUS de qualidade e universal.

Por outro lado, sabemos da importância para a saúde mental de "um sorriso interior em relação ao que somos e ao que temos". Em alguma medida, portanto, isso tem seu valor, ao relembrar que em praticamente toda situação humana há uma margem, mínima que seja, de agência no sujeito que pode ser explorada por ele mesmo, nem que seja apenas sobre si mesmo, como parece ser o enfoque das escrituras e da tradição do yoga. O incentivo ao contentamento e outras atitudes positivas vem sendo explorado por um 
campo emergente da psicologia, chamada de psicologia positiva. Esse movimento tem como objetivo principal a mudança do foco da psicologia tradicional, de uma atenção quase que exclusiva para as patologias e sofrimentos, para um olhar mais dedicado sobre as características positivas humanas. De acordo com essa abordagem, o contentamento está relacionado com a aceitação dos próprios sentimentos, a diminuição da autocriticidade e da raiva em relação aos outros e, à semelhança do yoga, com capacidade de se desprender de possíveis discrepâncias entre o que se quer e o que se tem ${ }^{29,30}$. O yoga e a psicologia positiva centram no desenvolvimento pessoal ao invés de um foco baseado em problemas. Por este motivo, entendemos que a inserção dessas abordagens e o diálogo entre elas poderia chamar a atenção dos profissionais que atuam em saúde mental para aspectos potencialmente sadios do usuário e sua exploração terapêutica. Assim, olhar para capacidades humanas, como a resiliência e o contentamento, em vez de voltar-se para a supressão de sintomas e controle das emoções, avançaria a atenção psicossocial na perspectiva da promoção da saúde, que em saúde mental tem reconhecidas dimensões terapêuticas.

O niyama seguinte, tapas, é geralmente traduzido por ascese ou disciplina. Tradicionalmente, esse valor yóguico é definido como o desenvolvimento da resistência às dualidades, como a fome e a sede, o frio e o calor, através de exercícios físicos e mentais como os exercícios posturais (asanas), as práticas de silêncio e os jejuns ${ }^{16}$.

Muito embora não carreguem essa conotação yóguica, vemos que muitas condutas que são sugeridas aos usuários da APS podem ser consideradas formas de ascese, como a prática de atividades físicas, a abstenção de hábitos nocivos, como alcoolismo e tabagismo e a orientação para dietas. Sem desconsiderar os benefícios potenciais dessas práticas, levantamos a ressalva que, dependendo dos discursos que as carregam, tais condutas podem adquirir contornos de "bioasceses" que, segundo Ortega ${ }^{31}$, estão mais voltadas para a uniformidade, para adaptação às normas e para a constituição de modos de existência conformistas. Diz o autor que, em um contexto marcado pela busca da saúde e do corpo perfeito e pela crença de que o fracasso em atingir essa meta deriva de uma fraqueza individual, as biosceses acabam por se tornar, elas mesmas, geradoras de aflições, adquirindo contornos clínicos de anorexias, transtornos de ansiedade e depressões $^{31}$. Diferentemente do conceito yóguico sobre a ascese, nas bioasceses contemporâneas o "eu" é progressivamente somatizado através de processos de modelamento e controle corporal. Enquanto que na bioascese contemporânea existe um empenho do indivíduo em "construir" uma identidade, através da ascese yóguica busca-se "revelar" uma identidade. Portanto, no contexto da APS a ascese sugerida pelo yoga não deve carregar qualquer tom disciplinar, que vise a normalização do indivíduo, mas deve surgir como uma proposta de experimentação, de tensionamento e abstinência com objetos (incluindo o próprio corpo) aos quais o indivíduo se encontra emocionalmente dependente.

Os dois últimos valores citados por Patañjali, autoestudo (svadhyaya) e contemplação à ishvara (ishvara pranidhana), estão bastante associados a religiosidade e espiritualidade indiana, respectivamente. $\mathrm{O}$ autoestudo envolve a leitura de textos considerados sagrados pelo hinduísmo, a recitação de cantos de louvor e a repetição de mantras voltados para divindades daquela cultura ${ }^{32}$. No hinduísmo, as divindades são compreendidas como diferentes aspectos de um mesmo princípio, chamado na linguagem do Yoga Sutra de purusha - aquilo que existe igualmente em cada indivíduo na forma de consciência. Através das práticas de auto-estudo o devoto desenvolve um relacionamento pessoal com sua divindade escolhida, de maneira que ela possa servir como uma representação simbólica desse princípio único.

Em relação ao último niyama, é necessário compreender o significado de ishvara, um termo de difícil tradução para o português, pois remete à um conceito que é próprio da cosmologia védica, na qual o yoga se insere. Consideramos pouco apropriado traduzir o termo por "Deus", como faz Eliade ${ }^{33}$, pois tal conceito diverge da filosofia de Patañjali. Visando fins práticos, podemos interpretar a "contemplação à ishvara" como o reconhecimento da existência de um esquema maior do que o indivíduo, uma ordem que governa ou pelo menos regula o mundo fenomênico, os eventos da vida. Na perspectiva de Patañjali, o reconhecimento dessa ordem permite com que o sujeito tenha uma atitude de relaxamento frente às diferentes, e às vezes adversas, situações de vida.

Considera-se atualmente que a espiritualidade e a religiosidade geralmente servem como fator positivo na capacidade do sujeito em lidar com adversidades da vida, tais como a solidão, a morte e os padecimentos ${ }^{34}$. Desde a assembleia mundial da saúde de 1983 que a OMS discute sobre a dimensão espiritual ou "não-material” da saúde, por considerar que percepções subjetivas, 
experiências e crenças influenciam no status objetivo da saúde e seu funcionamento no domínio físico, psicológico e social ${ }^{35}$. Toniol ${ }^{36}$ observa que os estudos do campo da saúde que exploram o tema da espiritualidade aumentaram exponencialmente nos últimos 40 anos, repercutindo na legitimação de abordagens relacionadas a essa dimensão no contexto da APS. Neste contexto, esses valores yóguicos se traduzem no respeito e incentivo à identidade religiosa e espiritual do usuário, considerando que essa é uma dimensão constitutiva do sujeito e que pode ter uma função terapêutica nas queixas relacionadas à saúde mental. Todavia, precisamos levantar algumas adaptações, pois se queremos explorar a contribuição dessas disciplinas yóguicas, temos que fazê-las a partir de uma atenção psicossocial que seja individualmente e culturalmente sensível. Ao adaptar o auto estudo para o contexto brasileiro, precisamos considerar o culto à outras divindades que não somente aquelas do panteão hindu, ou mesmo que a espiritualidade pode não envolver divindades. Compreendendo que todas as divindades sagram algum aspecto do universo, cada qual com sua singularidade, acreditamos que o valor do auto-estudo inclui o culto de outras religiões ou práticas espirituais, que pode aproximar o indivíduo de sua natureza que, de acordo com a filosofia do yoga, é livre de aflições mentais. Além disso, se uma pessoa não se identifica com a leitura da bíblia, dos vedas ou de qualquer texto religioso, acredita-se que o auto-estudo também pode se dar através da leitura de diversos escritores naturalistas, tais como Fernando Pessoa ${ }^{37}$, que celebram o aspecto divino presente na natureza.

\section{Considerações finais}

Para o desenvolvimento desse artigo, foram encontrados poucos estudos que relacionam a filosofia de Patañjali com o contexto da APS, sendo que a maior parte desses parecem compreender que tal filosofia consiste em uma prática, caracterizada basicamente por atividades posturais e respiratórias, de relaxamento e de meditação. Embora essa compreensão de yoga se desdobre em benefícios relevantes para a área da saúde, constatamos que essas atividades representam uma parcela da filosofia de Patañjali, e por extensão do próprio yoga. Além dessas práticas, o Yoga Sutra apresenta atitudes e comportamentos que intencionam gerar uma maior tranquilidade mental ao atenuar conflitos internos e externos, benefício que, no objetivo maior de sua filosofia, auxilia a pessoa no processo do autoconhecimento. A presença de princípios éticos como a nãoviolência, o não-consumismo e a não-possessividade significam uma crítica ao estilo de vida contemporâneo, caracterizado pela competitividade e pelo consumismo, que são vistos pela filosofia do yoga como geradores de angústias e aflições.

Assim, se o yoga está em um processo de expansão no SUS motivado pela PNPIC, espera-se e recomenda-se que a popularização de sua prática venha acompanhada por um igual interesse sobre essas bases conceituais, incluindo seus valores, objetivos e princípios norteadores, como forma de evitar que sua complexidade seja reduzida a alguma de suas partes constituintes, o que faria perder de vista o objetivo do yoga. Isso implica, tanto no âmbito acadêmico, quanto na 'ponta' (na relação do profissional interessado no yoga com a população em geral) em resgatar, interpretar e adaptar a filosofia do yoga de acordo com as aflições e queixas encontradas nos serviços de saúde da APS. E, mesmo que não haja queixas, a filosofia do yoga teria uma função adequada dentro da perspectiva da promoção da saúde mental, por apresentar diretrizes que conduzem para uma vida mais integrada e menos complicada. 


\section{Colaboradores}

LF Pereira participou da elaboração do projeto de pesquisa, análise e interpretação dos dados e redação final do artigo e CD Tesser, na orientação, redação e revisão crítica do artigo.

\section{Referências}

1. Brasil. Ministério da Saúde (MS). Portaria no 971/06. Dispõe sobre a integralidade da atenção como diretriz do SUS e aprova a Política Nacional de Práticas Integrativas e Complementares (PNPIC) no Sistema Único de Saúde. Diário Oficial da União 2006; 3 mai.

2. Brasil. Ministério da Saúde (MS). Portaria no 849/17. Inclui a Arteterapia, Ayurveda, Biodança, Dança Circular, Meditação, Musicoterapia, Naturopatia, Osteopatia, Quiropraxia, Reflexoterapia, Reiki, Shantala, Terapia Comunitária Integrativa e Yoga à Política Nacional de Práticas Integrativas e Complementares. Diário Oficial da União 2017; 28 mar.

3. Frosi RV, Tesser CD. Práticas assistenciais em saúde mental na atenção primária à saúde: análise a partir de experiências desenvolvidas em Florianópolis, Brasil. Cien Saude Colet 2015; 20(10):3151-3161.

4. Tesser CD, Sousa IMC. Atenção Primária, Atenção Psicossocial, Práticas Integrativas e Complementares e suas Afinidades Eletivas. Saude Soc 2012; 21(2):336350.

5. Caprara A. Uma abordagem hermenêutica da relação saúde-doença. Cad Saúde Pública 2003; 19(4):923931.

6. Arieira G. O yoga que conduz à plenitude: Os yoga sūtras de Patañjali. Rio de Janeiro: Sextante; 2017.

7. Feuerstein G. The lost teachings of yoga [CD-áudio]. Louisville: Sounds True; 2003.

8. Sugg JG. Dependence of the Yogasūtras on the Sāmkhya Kārikās [tese]. Oakland: Saybrook University; 2007.

9. Tesser CD, Barros NF. Medicalização social e medicina alternativa e complementar: pluralização terapêutica do Sistema Único de Saúde. Rev Saúde Pública 2008; 42(5):914-920.

10. Pacífica Graduate Institute. Clinical Psychology Dissertation Handbook. Capinteria: Pacifica Graduate Institute; 2016.

11. Feuerstein G. A Tradição do Yoga: história, filosofia e prática. São Paulo: Pensamento; 2006.

12. Palmer RE. Hermeneutics. Evanston: Northwestern University Press; 1969.

13. Sherma RD, Sharma A, organizadores. Hermeneutics and Hindu thought: toward a fusion of horizons. Berlim: Springer; 2008.

14. Gulmini L. O yogasutra de Patañjali: tradução e análise da obra, à luz de seus fundamentos contextuais, intertextuais e linguísticos [dissertação]. São Paulo: Universidade de São Paulo; 2002.

15. Prasada R, tradutor. Patañjali's yoga sutras: with the commentary of Vyasa and the gloss of Vachaspati Misra. New Delhi: Munishiram Manoharlal Publishers; 1998.

16. Bharati SV. Yoga Sutras of Patañjali: with the exposition of Vyasa - Sadhana-pada. Delhi: Motilal Banarsidass Publ.; 2004.

17. Rao R, Paranjpe A. Psychology in the indian tradition. New Delhi: Springer; 2016.

18. Farmer PE, Nizeye B, Stulac S, Keshavjee K. Structural violence and clinical medicine. PLoS Med 2006; 3(10):1686-1691. 
19. Gambhirananda S, tradutor. Bhagavad Gita: with the Commentary of Sri Sankaracharya. Calcutá: Advaita Ashrama; 2006.

20. Brusamarello T, Guimarães AN, Labronici LM, Mazza VA, Maftum MA. Redes sociais de apoio de pessoas com transtornos mentais e familiares. Texto Contexto Enferm 2011; 20(1):33-40.

21. Araujo MMT, Silva MJP, Puggina ACG. A comunicação não-verbal enquanto fator iatrogênico. Rev Esc Enferm USP 2007; 41(3):419-425.

22. Ahuvia A, Izberk-Bilgin E. Well-Being in Consumer Societies. In: David SA, Boniwell I; Ayers AC, organizadores. Oxford Handbook of Happiness. Reino Unido: Oxford University Press; 2013. p. 482-497.

23. Illich I. A expropriação da saúde: nêmesis da medicina. Rio de Janeiro: Nova fronteira; 1975.

24. Iyengar BKS. Light on the Yoga S tras of Patañjali. London: Thorsons; 2002.

25. Alter JS. Celibacy, Sexuality, and the Transformation of Gender into Nationalism. J Asian Studies 1994; 53(1):45-66.

26. Agência Nacional de Vigilância Sanitária (ANVISA). Instrução normativa $\mathrm{n}^{\circ} 02$, de 13 de maio de 2014. Publica a "Lista de medicamentos fitoterápicos de registro simplificado" e a "Lista de produtos tradicionais fitoterápicos de registro simplificado". Diário Oficial da União; 2014.

27. Brasil. Ministério da Saúde (MS). Secretaria de Atenção à Saúde. Departamento de Atenção Básica. Cadernos de Atenção Básica - $n^{\circ}$. 34. Brasília: MS; 2013.

28. Dinan TG, Stanton C, Cryan JF. Psychobiotics: a novel class of psychotropic. Biol Psychiatry 2013; 74(10):720-726.

29. Selingman MEP, Csikszentmihalyi M. Positive psychlogy: an introduction. Am Psychol 2000; 55(1):5-14.

30. Henry J. Quieting the mind and low arousal routes to happiness. In: David SA, Boniwell I, Ayers AC, organizadores. Oxford Handbook of Happiness. Reino Unido: Oxford University Press; 2013. p. 411-424.

31. Ortega F. Práticas de ascese corporal e constituição de bioidentidades. Cad Saúde Colet 2003; 11(1):59-77.

32. Bharati SV. Yoga Sutras of Patañjali with the exposition of Vyasa - Samadhi-pada. Pensilvânia: Himalayan International Institute; 1986.
33. Eliade M. Yoga: Immortality and freedom. Bollingen series LVI. New York: Bollingen Foundation; 1958.

34. Pargament KI, Koenig HG, Perez LM. The many methods of religious coping: Development and initial validation of the RCOP. J Clin Psychol 200; 56(4):519543.

35. Organização Mundial da Saúde (OMS). WHOQOL and Spirituality, Religiousness and Personal Beliefs (SRPB). WHO department of mental health. Genebra: OMS; 1998.

36. Toniol R. Espiritualidade que faz bem: Pesquisas, políticas públicas e práticas clínicas pela promoção da espiritualidade como saúde. Soc Relig 2015; 25(43):110-146.

37. Pessoa F. Poemas completos de Alberto Caiero. Rio de Janeiro: Ed. Cia das Letras; 2005.

Artigo apresentado em 20/10/2018

Aprovado em 17/04/2019

Versão final apresentada em 19/04/2019

Editores chefes: Romeu Gomes, Antônio Augusto Moura da Silva 